\title{
I am the Paradigm Shift Theory: Explaining Students' Sustainability Outcome Comprehension Experience
}

\section{Chandler $\mathbf{R}^{*}$}

Department of Psychology, College of Liberal Arts and Sciences, University of Florida, USA

*Corresponding author: Ron Chandler, Sustainability Psychologist, Environmental

\section{Research Article}

Volume 2 Issue 5

Received Date: November 13, 2017

Published Date: December 21, 2017

Scientist; Lecturer Department of Psychology, College of Liberal Arts and Sciences; University of Florida, USA, E-mail: ronchandler@ufl.edu

\section{Abstract}

Students receiving a liberal arts education develop the prosocial outcomes of inclination to inquire and lifelong learning, well-being, leadership, intercultural effectiveness, post conventional moral reasoning, and reflective judgment more effectively than career track institution counterparts. Researchers in efficacy of the liberal arts as well as in sustainability education have expressed the need for descriptive theory to guide further research towards understanding of learners' comprehension experience of these essential outcomes and for developing effective sustainability education. In an effort to describe characteristics most common to the successful sustainability student the author found that these characteristics were in essence identical to the prosocial outcomes of liberal arts students. Through a constructivist grounded theory approach, the author sought to describe students' comprehension experience of sustainability (i.e. prosocial) outcomes. Four central phenomena were synthesized from the data: nature as resolve, fear mastery, paradigm shift, and new normal. These phenomena were used to construct I am the paradigm shift theory which describes students' comprehension experience of sustainability outcomes. The importance of I am the paradigm shift theory is three fold: First, it provides additional understanding of perspectives on sustainability outcome comprehension hitherto quantitatively explored. Second, it describes the sequential and reciprocal experience of sustainability outcome comprehension. Third, the theory illuminates the influence of early efficacy, and esteem affirmation motivation and perseverance in outcome comprehension. Needs for further research and limitations of the study and also discussed.

Keywords: Climate Change, Field Guide; I am the Paradigm Shift Theory; Liberal Arts Education; Sustainability; Sustainability Education; Sustainability Outcomes

"The educator must believe in the potential power of his pupil, and he must employ all his art in seeking to bring his pupil to experience this power." Alfred Adler 


\section{Psychology \& Psychological Research International Journal}

\section{Introduction}

Profligate use of Earth's resources has and continues to produce comprehensively catastrophic social and environmental consequences. Consensus exists across the environmental sciences that phenomena resulting from humanity's exploitation of Earth including but not limited to climate destabilization, water shortage, desertification, fisheries and food systems collapse, sea level rise, extinction, and consequent mass displacement of human beings and built habitation are on course to fully manifest within the next 100 years [1-4]. Moreover, consensus exists across the social sciences that avoiding the worst outcomes of this comprehensive problem will require behavior change, ingenuity, and cooperation unprecedented in the history of our species [5-7]. Critical to this effort is holistic sustainability, the ecologically continuous response to factors affecting human dignity and human ecology [8-14]. A holistic approach to sustainability is proffered by scholars across the natural and environmental sciences [15-17], social sciences [1821], commerce and economics [22-24], and humanities as the most effective approach towards resolving this comprehensive problem [25-28].

Students receiving a liberal arts education develop the prosocial outcomes of inclination to inquire and lifelong learning (hitherto interest in lifelong learning), wellbeing, leadership, intercultural effectiveness, post conventional moral reasoning, and reflective judgment (Table 1) more effectively than their career track institution counterparts [29-33]. Through research described in this article it was determined that the aforementioned prosocial outcomes were remarkably similar to the characteristics demonstrated by effective sustainability students. Therefore Chandler (2014) adopted these outcomes as sustainability outcomes for use in describing sustainability students' outcome comprehension experience.

Researchers in efficacy of the liberal arts and sustainability education $[34,35]$ have expressed the need for descriptive theory to guide further research and development of educational approaches to sustainability. Understanding students' comprehension experience of sustainability outcomes is important, as individuals possessing these outcomes will be more capable to effectively address sustainability problems in context $[20,36,37]$. Therefore limited understanding of students' comprehension experience of sustainability is a problem and the need for theory describing this experience is a gap that must be filled.

\section{Outcome and Definition1}

Post conventional moral reasoning: concerns the use of moral ideals, theories, and concepts that may not be normative for resolving complex issues in sociocultural context.

Reflective reasoning: refers to the capacity to take stock in past experiences, lessons, decisions, and positions, and to consider these in the context of current issues toward problem solving.

Leadership: pertains to an individual's consciousness of self, congruence, commitment, collaboration, and common purpose.

Wellbeing: pertains to an individual's autonomy, positive relationship with others, environmental mastery, personal growth, and life purpose.

Intercultural effectiveness: generally concerns individual ability to synthesize information and problem solve in sociocultural contexts.

Interest in lifelong learning: pertains to an individual's enjoyment of engaging in varied and challenging learning activities and their interest in sharing knowledge gained from these activities.

Table 1: The Study: Describing Students' Sustainability Outcome Comprehension Experience.

The objective of this study was to two fold. First, to identify if and when the sustainability outcomes of interest in lifelong learning, well-being, leadership, intercultural effectiveness, post conventional moral reasoning, and reflective judgment became operational in students' academic career. Second, to describe students' comprehension experience of these outcomes. Towards meeting this objective a substantive theory explaining students' comprehension experience of sustainability outcomes was constructed.

\section{Method}

\section{Participants and Experimental Design}

Fifteen participants were conveniently and purposefully sampled from senior-year sustainability students at a small liberal arts college in Northeastern US. Sampling was convenient as well as purposeful. All participants were at least 18 years of age, and English was their primary language. Students were from varied 


\section{Psychology \& Psychological Research International Journal}

socioeconomic, sociocultural, and socioecologically backgrounds, and there were near-equal number of male and female participants. Secondary sources of data were not used, and members of vulnerable and protected populations were not sampled. This study employed constructivist grounded theory for exploration four openended research questions with all participants $(N=15)$ through semi structured interviews [38].

Grounded theory is appropriate when theory pertaining to a phenomenon of interest does not exist or extant theories appear to be falling short of guiding development of understanding about a phenomenon [3840]. Furthermore, qualitative researchers consider grounded theory to be best suited for exploring complex sociocultural, psychosocial, and socioecologically processes, and for developing substantive theory explaining these processes.

\section{Materials and Procedure}

Through the employment of constructivist grounded theory data acquisition and analysis were performed along a continuum of sequential procedures requiring multiple interviews [41,42]. Four interviews were conducted with each participant and served to provide primary data acquisition and analysis (first interview; open coding), secondary data acquisition and analysis (second interview; axial coding), tertiary data acquisition and analysis (third interview; selective coding), and final vetting of the theory paradigm, model, and narrative (fourth interview).

All interviews were recorded with a digital voice recorder and supplemented with memos taken during interviews using a Smart Pen $^{\mathrm{TM}}$ (digital pen) on Livescribe ${ }^{\circledR}$ Dot Paper ${ }^{\mathrm{TM}}$. A high-resolution audio recorder was integral to the digital pen, thus providing redundant voice records. Data from the voice recorder and digital pen were uploaded to NVivo ${ }^{\mathrm{TM}}$, a computerassisted qualitative data analysis system (CAQDAS) application $[43,44]$. The four open-ended research questions used to guide these interviews were as follows.

- Do you attribute the influence of a person or group, events, and/or places to their decision to pursue this education at this college?

- Do you identify an event, time, or place where they feel the overall importance of their education became obvious or where a sense of purpose of their work going forward coalesced?

- Do you attribute their perspectives on the future to experiences at the college and in their program of study? How do they describe their perspectives?
- Have you developed an image of sustainable society? If so, do they have a sense of their role(s) in manifesting this?

\section{Results and Discussion}

Sustainability outcomes became operational and endured beginning at different times in participants' comprehension experience. Figure 1 provides an example of results of open coding and first "appearance" of sustainability outcomes. During the interview process, a note was made for each participant when it first appeared that a sustainability outcome was in operation. Further memos were taken when it was clear that an outcome had become and was remaining operational in a participant's experience.

Results Pertaining to Individual Research Questions and Origins of Central Theory Phenomena

Do students attribute their decision to pursue this education at this college to the influence of a person or group, events, and/or places?

Prior to exploring the research questions participants were introduced to the sustainability outcomes. Each participant mentioned an intuitive experience of reflective judgment and post-conventional moral reasoning. Recall that reflective judgment and postconventional moral reasoning are among the six outcomes $[45,46]$ that are necessary for effecting sustainability, and that development of these outcomes is characteristic of and all but unique to liberal arts education [33]. Common to all participants' responses regarding the first research question was the influence of an especially vital mentor. This mentor was coded as field guide. Participants' field guides were especially influential in attuning them to nature in general and occasionally to specific aspects of nature for example wildlife, natural landscapes, and/or to the needs of marginalized peoples. In general, the field guide also conveyed unconditional appreciation for the participant and encouraged them to pursue the things that they loved. A field guide appeared in most participants' early adolescence however but for some participants a field guide was recognized in midchildhood. Reflective judgment and post-conventional moral reasoning served referentially and inspirationally throughout learners' comprehension experience of sustainability outcomes, and became operative for all participants at some point in their comprehension experience.

According to environmental identity theorists [47], a vital mentor, in the context of this study, a field guide, can profoundly affect attention to and development of individual social value orientation and environmental 


\section{Psychology \& Psychological Research International Journal}

identity [48-51]. An interesting condition was that for most participants their field guide was a teacher or community leader, not their parents, and when a parent was identified as a field guide it was principally their mother. Participants' field guides invariably and positively facilitated their development of self-esteem and self-efficacy, as well as influenced their choice of degree program and college. An excerpt from one participant's response represents this common experience.

"We [teacher and student] met every day and talked about environmental issues and solutions...I want to give every kid I can find what he gave me. That's why I'm here."
It is helpful to stop here and introduce the initial data categories resulting from analysis of the first interview. During the first interview the four secondary questions were explored with each participant. Data from these interviews were thematically organized within three categories named source field, unity field, and future focus (Figure 1). Recall that the research questions were constructed to facilitate conversation about participants' experiences related to their sustainability outcome comprehension before and during their college career, as well as how they imagined these experiences affecting their future. These category names were selected from

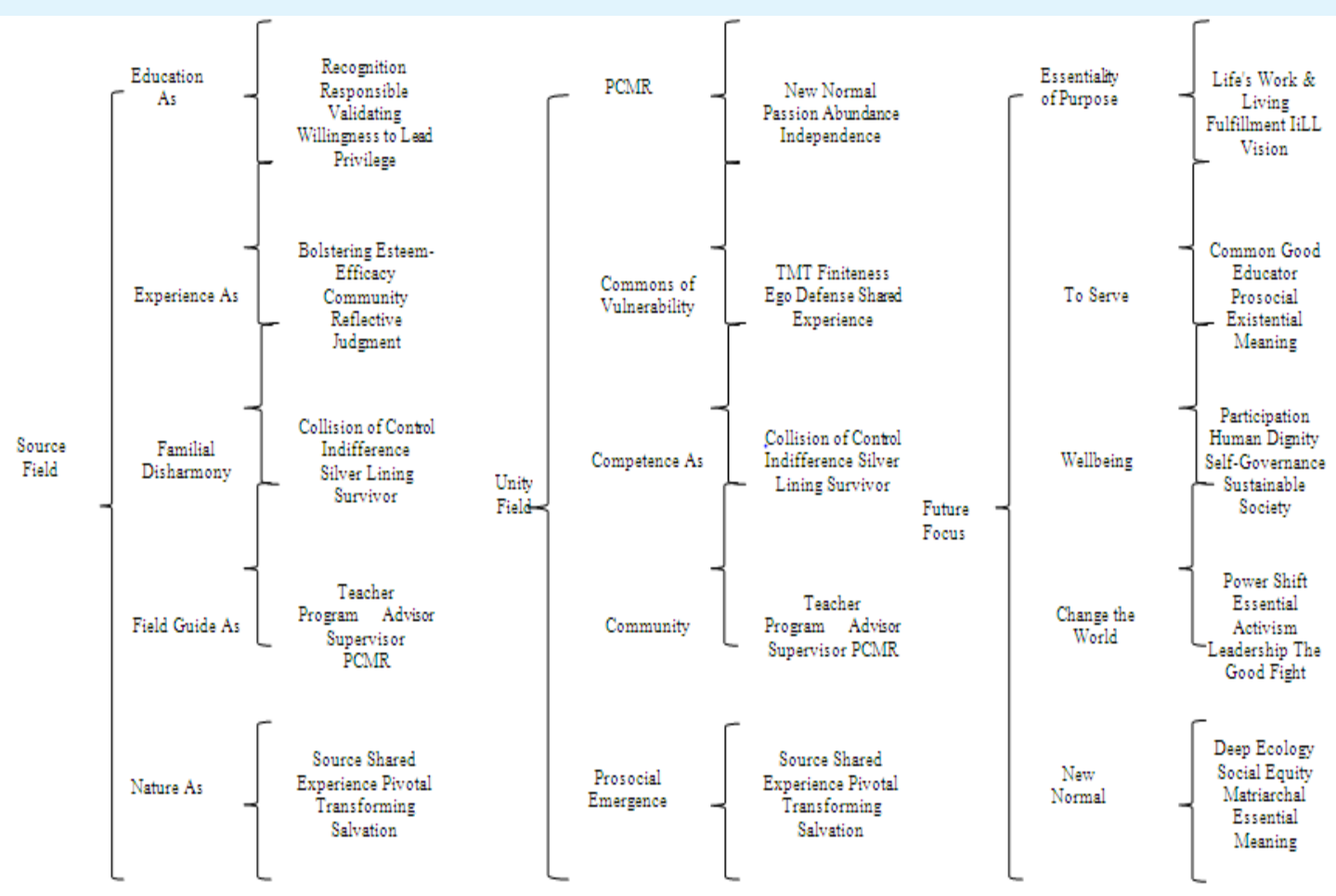

Figure 1: example of initial coding of data: categories, subcategories, and themes. Data from the first interview were categorized as source field, unity field, and future focus. Data were taken from one participant's database and serve as an example of early analysis. $\mathrm{Pcmr}=$ post-conventional moral reasoning. $\mathrm{I}$ ill $=$ interest in lifelong learning.

Interview content and represented the first attempt at synthesizing interview data towards a construction of a descriptive theory explaining students' sustainability outcome comprehension experience. While not exclusively, data acquired through exploration of the first question were coded as subcategories and themes within the category source field (Figure 1). Further analysis of source field data would inform the construction of the central phenomenon nature as resolve (Table 2, Figure 2).
Do students identify an event, time, or place where they feel the overall importance of their education became obvious or where a sense of purpose of their work going forward coalesced? Do students attribute their perspectives of the future to experiences at the college and in their program of study? How do they describe their perspectives?

Participants frequently shared thoughts on the meaning of the second and third questions together. They 


\section{Psychology \& Psychological Research International Journal}

did so to such an extent that it was virtually impossible to draw defensible divisions between data gathered from discussion of these questions. Consequently, the following discussion combines data acquired through exploration of the second and third secondary question. In varying ways all participants shared an early experience of overcoming a state of trepidation even terror regarding attending college and their degree choice. Analysis of the many versions of this experience was coded within the category freshman fright (Figure 1). The essence of freshman fright was found in one participant's comment, "The first time after registration that I set foot on campus I said oh my God what have I done?"

Tantamount in importance in participants transcendence of freshman fright was reflective judgment, post-conventional moral reasoning, and leadership. Leadership entailed simultaneous awareness of one's needs in continuity with and commitment to collaboration for a common purpose and typically, this common purpose was about prosocial change. During exploration of second and third questions, participants revealed that leadership had become salient first as a personal responsibility and later, as a responsibility to others. Put another way, participants employed reflective judgment and post-conventional moral reasoning to reaffirm their college and degree choice thus continuing to self-motivate and self-direct, and afterwards recognized their responsibility to help others do the same. One participant's statement exemplifies participants' transcendence of freshman fright, and the appearance and progression of leadership in students' comprehension experience.

"I showed up to take action... I felt that I'd find others that would join me...and they did. There is a lot of faith, a lot of hope; you just gotta keep that...."

Many themes were identified and coded in context of freshman fright, including emerging into emergency, mindfulness, evolution of voice, life as experience, and fear mastery (Figure 1), and each were important in construction of central phenomena and theory. Fear master would eventually be developed as one of the central phenomenon of students' sustainability outcome comprehension experience (Table 2, Figure 2). In addition to leadership, the sustainability outcomes of wellbeing, intercultural effectiveness, and interest in lifelong learning were observed among all participants during exploration of second or third question. As with each outcome, once operational wellbeing, intercultural effectiveness, and interest in lifelong learning remained influential throughout participants' comprehension experience.

Category and Subcategory Ranking by Number of Propositions

\begin{tabular}{|c|c|c|c|c|c|}
\hline Categories & $\begin{array}{c}\text { Category-Category } \\
\text { Propositions }\end{array}$ & $\begin{array}{c}\text { Cat-Cat } \\
\text { Ranking }\end{array}$ & Subcategories & $\begin{array}{c}\text { Sub Category-Sub Category } \\
\text { Propositions }\end{array}$ & $\begin{array}{c}\text { Sub Cat-Sub } \\
\text { Cat Ranking }\end{array}$ \\
\hline $\begin{array}{c}\text { Nature as Resolve: } \\
\text { NaR }\end{array}$ & $\begin{array}{c}\text { NN, EiE, NaR, Arch, SRSD, } \\
\text { FH, GM, SoV, EoV, VaS, U, }\end{array}$ & 11 & New Normal: NN & $\begin{array}{c}\text { PS, EoV, U, MF, SoV, LaL, } \\
\text { FM, NaR, NN, SaV, }\end{array}$ & 19 \\
\hline New Normal: NN & $\begin{array}{c}\text { PS, EoV, U, MF, SoV, LaL, } \\
\text { FM, NoR, NN, SaV, }\end{array}$ & 9 & Paradigm Shift: PS & $\begin{array}{c}\text { EoV, FM, NN, PM, GM, EiE, } \\
\text { FH, NaG, MF, }\end{array}$ & 19 \\
\hline Paradigm Shift: PS & $\begin{array}{c}\text { EoV, FM, NN, PM, GM, EiE, } \\
\text { FH, NaG, MF, }\end{array}$ & 9 & Fear Mastery: FM & $\begin{array}{c}\text { EiE, NN, MF, PS, U, FH, } \\
\text { EoV, FM, }\end{array}$ & 17 \\
\hline Fear Mastery: FM & $\begin{array}{c}\text { EiE, NN, MF, PS, U, FH, EoV, } \\
\text { FM, }\end{array}$ & 8 & $\begin{array}{c}\text { Nature as Resolve: } \\
\text { NaR }\end{array}$ & $\begin{array}{c}\text { NN, EiE, NaR, Arch, SRSD, } \\
\text { FH, GM, SaV, EoV, VaS, U, }\end{array}$ & 14 \\
\hline
\end{tabular}

Note: Researcher and participants constructed categories and subcategories (15 each). Four of each had the highest number of individual (category-category; subcategory-subcategory) propositions as well as thematically combined (category-subcategory) propositions. These were used to construct the axial coding paradigm. Arch $=$ Naturalist as Architect of New Humanity; EiE = Emerging into Emergency; EoV = Evolution of Voice; FH = Finding Home; FM = Fear Mastery; GM = Grief Mastery; LaL = Life as Landscape; MF = Mindfulness; NaG = Nature as Gift; NaR = Nature as Resolve; NN = New Normal; PM = Passion Mastery; PS = Paradigm Shift; SaV = Self as Voice; U = Unification; VaS = Voice as Self.

During exploration of the second and third questions, leaners' reflected upon experiences of validation and coalescence regarding college and their program choice. In addition, they recognized heightened awareness of the importance of experiences through college in thoughts about their careers that included importance of becoming a global citizen. Of the many statements about participants' experience of validation and coalescence, one participant's observation seemed exemplary.

"I had worked as a wilderness emergency medical technician (WEMT) and thought that this would be my 


\section{Psychology \& Psychological Research International Journal}

career. But the more that I worked and studied in the field with groups from the college the more I realized that WEMT was a window to what is needed for healing... Wilderness and psychology, where head and heart meet... this will be my career."

Emergent self, grief mastery, dream empowerment, and woman as strength (Table 2, Figure 2) were among the themes developed to illustrate the operation of wellbeing in participants' comprehension experience. Of the many examples of wellbeing in operation the following participants' statements are among the most representative.

\section{"Life is a practice not a product."}

"I recognized that if I am to be a healer of the human condition I first had to overcome the grief that I felt about what has already happened."

As previously mentioned, intercultural effectiveness was observed for all participants during exploration of the second and third questions. Among the many themes that illuminated intercultural effectiveness during these interviews were commons of vulnerability, membership, serve and protect, non-human animal dignity, matriarchy, and to interact with the world (Figure 1). Two examples of participants' expressions of intercultural effectiveness were:

"Everything that happens does so because of social justice or lack of it."
"Considering humility as a strength helps us to interact with the world."

As previously mentioned, interest in lifelong learning was observed among all participants during exploration of the second and third questions. Interest in lifelong learning was especially influential in participants' contemplations of the future. Learners experienced interest in lifelong learning as an aspect of continued selfawareness as well as an aid in sharing knowledge with others. Following were two of the many examples of participants' expression of interest in lifelong learning.

"My self continues to emerge...it is a process. It's important to not get stuck and to continue this evolution of self."

"If I could study and teach the rest of my live I would never be bored."With few exceptions taking direct action on resolving factors effecting the comprehensive social problem of unsustainable behavior characterized participants' vision of their life's work. They attributed this perspective to experiences provided through the college. Many themes were identified during exploration of the second and third questions with respects to the vision of taking action to resolve the comprehensive problem including finding home, grief mastery, evolution of voice, convergence, paradigm shift, power shift, and new normal. Analysis of data comprising these themes would inform the construction of the central phenomenon paradigm shift (Table 2, Figure 2).

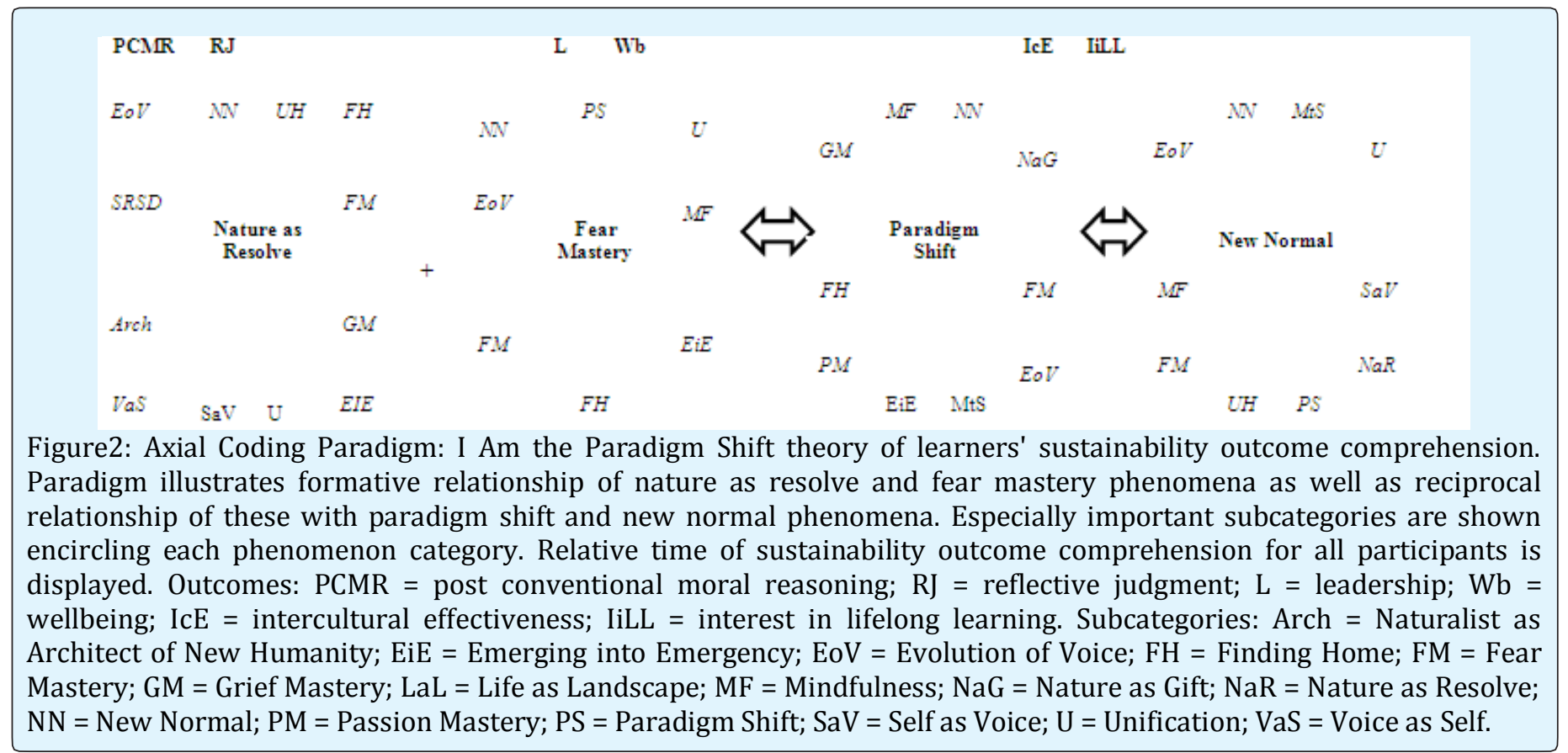




\section{Psychology \& Psychological Research International Journal}

Following were a few of the many examples of participants' visions of their life's work.

"If you want something bad enough you have to fight for it. People need to learn how to fight... I'm going to teach people how to fight for themselves."

"Sustainability is a social problem first not a science problem...I intend to teach people how to see it this way."

"Free me from this dead doomsday message. I am not going to wait for a paradigm shift I am the paradigm shift!"

Have learners developed an image of sustainable society? If so, do they have a sense of their role(s) in manifesting this?

Participants' thoughts pertaining to the fourth question were widely varied. Myriad themes from these discussions would initially be used to construct the category of future focus (Figure 1). A few participants imagined sustainable community as intentional, one that they would create and build throughout their lifetime; that is a sustainable community would essence be their life's work. Other participants described a sustainable community as one that in general served the common good as much as or more so than individual interests: that is collectivist. Still others envisioned a sustainable society as being a combination of both views (intentional and constructed, and collectivist) but with matriarchal governance.

Finally, a majority of participants envisioned a sustainable society as an ever-evolving form of life's work characterized by a human ecological approach to increasing a appreciation of social capital and redevelopment of built environments such that neighborhoods would function as sustainable villages integrated within the natural landscape as has been suggested by Chandler (2009) and Rosenzweig (2003). Themes such as solidarity community, commons of vulnerability, reconciliation ecology, lot, block, and neighborhood, human ecology as synthesis, good fight, woman as strength, and purpose as home were developed as themes within the category of future focus (Figure 1). Analysis of data comprising the category future focus would inform the construction of the central phenomenon new normal (Table 2, Figure 2). Following were a few of the many examples of participants' visions of a sustainable society. It is appropriate to report a number of participants' statements given the diversity of visions conjured in response to the fourth question. “...when you're in the city and can see the stars, which will be an indication that we're sustainable."

"...one where currency is social, social capital, anyone that can contribute to the common good can afford to live there because their contribution has value, monetary value is irrelevant."

"Sustainable society? Well part of it is about fighting the good fight and getting others to do the same."

"Life is a landscape so it doesn't really matter where you are as long as you're doing all that you can."

"Well where do we need to go to change the world? That's where I'm going."

"Community comes through solidarity and happens for a cause."

\section{Central Phenomena and Theory Construction}

As previously mentioned, through selective coding it was determined that students' comprehension experience of sustainability outcomes occurs sequentially as well as reciprocally through the interaction of four central phenomena: nature as resolve $(\mathrm{NaR})$, fear mastery $(\mathrm{FM})$, paradigm shift (PS), and new normal (NN), respectively (Table 2). It was also determined that comprehension of sustainability outcomes arises from as well as gives rise to the central phenomena. Following is a description of each phenomenon that includes the sustainability outcomes that became and remained operative through the phenomenon.

\section{Central Phenomena}

Nature as resolve: Post conventional Moral Reasoning and Reflective Judgment: For most participants, Nature was experienced through non-human aspects of life on Earth, but for a few Natures was also and even predominantly experienced through needs of marginalized peoples. Nature was the purpose for or experience through which participants developed their resolve to begin their program of study. Through the continuum of comprehension experience, nature as resolve uniquely served each participant as a validating, positive, and reflexive experience.

\section{Fear mastery: Leadership and Wellbeing}

Participants transcended fear of the unknown and maintained motivation to continue their program of study in light of increasing awareness that they would be 


\section{Psychology \& Psychological Research International Journal}

working in societies wracked by the social dilemma. Participants expressed that fear mastery was the experience of recognition of strengths and weaknesses, and that this understanding facilitated a desire to be effective leaders on their behalf as well as on behalf of others. Fear mastery was a recurring experience.

\section{Paradigm shift: Intercultural Effectiveness and Interest in Lifelong Learning}

Differing from conventional understanding, paradigm shift here was not an outcome, but rather it was an action and a process. Moreover, when the individual served as paradigm shift they catalyzed action necessary to create and maintain sustainable human ecology. Each participant recognized that in similar and dissimilar ways they must serve as paradigm shift if meaning of nature as resolve and fear mastery are to remain valid in the present and accessible in the future. Paradigm shift was experienced as an ever-present ever-evolving understanding of one's self as an effective prosocial actor.

\section{New normal: All Outcomes Present and Operative}

Simply put, participants experienced new normal as a future scenario and one of an ever-evolving creation of sustainable human ecology. For participants, new normal could not be manifested without placement of power renormed to the people to such an extent that prosocial change could be holistically implemented and that translated to sustainability. Participants saw sustainable human ecology as a continuum of improvement toward just treatment of Earth and all her inhabitants.

Nature as Resolve and Fear Mastery were considered by participants to be the foundational phenomena and essential to the development of a sustainable human ecology. However, without the catalyzing effect of Paradigm Shift, Nature as Resolve and Fear Mastery would remain unorganized as nothing more than improvements of the existing norm. Paradigm shift was considered essential to raise society to the highest level of an ever-evolving organization: new normal.

\section{Theory Construction}

In addition to providing data necessary for development of the four central phenomena, research also identified four principles of participants' comprehension experience were useful for explaining the relationships between phenomena and the roll of phenomena in students' comprehension experience. These four principles were also used to guide theory construction and are described as follows.

- Comprehension of sustainability outcomes arises from as well as gives rise to the central phenomena.
- There is temporality and spatiality shared between outcome comprehension and central phenomena. That is, phenomena are sequential psychosocial experiences within learners' comprehension experience without which comprehension would be unlikely.

- The reciprocal relationship of phenomena, sustainability outcome comprehension, and employment of sustainability outcomes depends most upon the role of the individual as the paradigm shift.

- The individual acting as paradigm shift serves as a catalyst through which nature as resolve and fear mastery are reflexively employed in the context of the aspiration of the phenomena described by the new normal.

Participants unanimously considered of the phenomenon Paradigm Shift to be of critical importance to their comprehension experience of sustainability outcomes so much so one participant's statement during the final interview, "I am not waiting for a paradigm shift, I am the paradigm shift!" was unanimously accepted as the theory name: I am the paradigm shift theory. Figure 2 presents I am the paradigm shift theory model the construction of which was informed through interview data and guided by the aforementioned principals. The model illustrates the sequential as well as reciprocal relationship of the four central phenomena in students' comprehension experience of sustainability outcomes, as well as the relative appearance of these outcomes.

\section{Conclusion and Recommendations}

\section{Conclusion}

Consensus exists across the environmental sciences that phenomena resulting from humanity's exploitation of Earth including but not limited to climate destabilization, water shortage, desertification, fisheries and food systems collapse, sea level rise, extinction, and consequent mass displacement of human beings and built habitation are on course to fully manifest within the next 100 years [1-4]. Moreover, consensus exists across the social sciences that avoiding the worst outcomes of this comprehensive problem will require behavior change, ingenuity, and cooperation unprecedented in the history of our species [5-7]. Critical to this effort is holistic sustainability, the ecologically continuous response to factors affecting human dignity and human ecology [8-14]. A holistic approach to sustainability is proffered by scholars across the natural and environmental sciences, social sciences [15-21], commerce and economics, and humanities as the most effective approach towards resolving this comprehensive problem [22-28]. 


\section{Psychology \& Psychological Research International Journal}

Students receiving a liberal arts education develop the outcomes of interest in lifelong learning, well-being, leadership, intercultural effectiveness, post conventional moral reasoning, and reflective judgment (Table 1) more effectively than their career track institution counterparts [29-33]. The aforementioned outcomes are remarkably similar to the characteristics demonstrated by effective sustainability students and have been adopted as sustainability outcomes for use in describing sustainability students' outcome comprehension experience. Researchers in efficacy of the liberal arts and sustainability education have expressed the need for descriptive theory to guide further research and development of educational approaches to sustainability. Understanding students' comprehension experience of sustainability outcomes is important, as individuals possessing these outcomes will be more capable to effectively address sustainability problems in context $[34,37]$.

Results of this study are clearly relevant in the context of observations made by Seifert, et al. (2008) [33]. For example it appears that post-conventional moral reasoning and reflective judgment are operative with students prior to comprehension of other outcomes, and that these outcomes are likely operative in students' decision-making processes regarding college enrollment and in choosing their programs of study. Therefore, it is likely that items and operationalizations by Seifert et al. (2008) were not errant as they had posited with respects to post-conventional moral reasoning and reflective judgement, rather it is plausible that these outcomes could share an essential formative phenomenon (e.g., field guide) as was observed in the sustainability outcome comprehension experience described by I am the paradigm shift theory.

\section{Recommendations}

Experts in the areas of climate destabilization, water shortage, desertification, fisheries and food systems collapse, sea level rise, extinction, and consequent mass displacement of human beings and built habitation assert that without implementation of holistic sustainability across all sectors of society, the chances for avoiding the worst of outcomes resulting from this comprehensive problem are poor.

In general, contributions of I am the paradigm shift theory are through improvement of sustainability education, future research for sustainability action, and positive social change in the following ways. More specifically, students' comprehension experience of sustainability outcomes has temporality strongly influenced by experience. Therefore it appears clear that any effort to modify or develop programming for sustainability education should be guided at least in part by I am the paradigm shift theory (IPST). Benefits of the employment of IPST range from the provision of a basic understanding of the psychosocial factors affecting students' sustainability outcome comprehension to serving as a principal tenet guiding sustainability education program development and improvement. For example IPST could be used to develop approaches that will accelerate comprehension of sustainability outcomes, create outreach materials for sustainability programs, improve representativeness of existing sustainability education assessment instruments, and to develop flexible sustainability education models that are socio culturally and socioecologically continuous.

\section{References}

1. Barnosky A, Hadly E, Bascompte J, Berlow E, Brown J, et al. (2012) Approaching a state shift in Earth's biosphere. Nature 486: 52-58.

2. Carbon Tracker (2012) Unburnable Carbon: Are the world's financial markets carrying a carbon bubble? London, UK, Pp: 33.

3. Hansen J, Kharecha P, Sato M (2013) Climate forcing growth rates: Doubling down on our Faustian bargain. Environmental Research Letters 8(1).

4. Mann M (2012) Hockey stick and climate wars: Dispatches from the front lines. Columbia University Press.

5. American Psychological Association (2009) Psychology and global climate change: Addressing a multi-faceted phenomenon and set of challenges (A report by the American Psychological Association's task force on the interface between psychology and global climate change). Washington, DC: Author.

6. Pike C, Dopplet B, Herr M (2010) Climate communications and behavior change: $A$ guide for practitioners. Institute for a Sustainable Environment, University of Oregon.

7. Rockström J, Steffen $\mathrm{W}$, Noone K, Persson $\AA$, Chapin III S, et al. (2009) Planetary boundaries: exploring the safe operating space for humanity. Ecology and society $14(2): 32-55$

8. Barrett B, Grizzle R (1999) A holistic approach to sustainability based on pluralistic stewardship. Environmental Ethics 21(1): 23-42. 


\section{Psychology \& Psychological Research International Journal}

9. Chandler R (2008) Sustainable communities and civic engagement: From Texas to Thailand. Paper presented as the keynote address for Dream Green Week, TWU, Denton, TX.

10. Chandler R (2009) Resolving sustainability at the lot, block and neighborhood scale. Paper presented at the Water, Wetlands and Watersheds Symposium, Gainesville, FL.

11. Chandler R (2010a, February) Lifespan development and our relationship with water. Paper presented at the $2^{\text {nd }}$ Annual Water Symposium, Gainesville, FL.

12. Chandler R (2010b, August) Transdisciplinary approach to sustainability education. Workshop held at the SENCER Symposium of the 21 $1^{\text {st }}$ Biennial Conference on Chemical Education, University of North Texas, Denton, TX.

13. Cuello C (1997) Toward a holistic approach to the ideal of sustainability. Philosophy and Technology 2: 41-48.

14. Häni F, Braga F, Stämpfli A, Keller T, Fischer M, et al. (2003) RISE, a tool for holistic sustainability assessment at the farm level. International Food and Agribusiness Management Review 6(4): 78-90.

15. Dickinson J (2009) The people paradox: self-esteem striving, immortality ideologies, and human response to climate change. Ecology and Society 14(1): 34-50.

16. Rosenzweig M (2003) Reconciliation ecology and the future of species diversity. Oryx 37(2): 194-205.

17. Childers D, Pickett S, Grove J, Ogden L, Whitmer A (2014) Advancing urban sustainability theory and action: Challenges and opportunities. Landscape and Urban Planning 125: 320-328.

18. Howard GS (2000) Adapting human lifestyles for the 21st Century. American Psychologist 55(5): 509-515.

19. Oskamp S (2002) Environmentally responsible behavior: Teaching and promoting it effectively. Analysis of Social Issues and Public Policy 2(1): 173182.

20. Chandler R (2014) I am the Paradigm Shift: A Grounded Theory of Learners' Sustainability Outcome Comprehension Experience. Ann Arbor, MI: ProQuest.

21. Pilisuk M, Joy M (2014) Humanistic psychology and ecology. The Handbook of Humanistic Psychology: Theory, Research, and Practice 135.
22. Fonseca LM (2015) Sustainability: The Journal of Record 8(3): 136-142.

23. Lawler III EE (2014) Sustainable Effectiveness and Organization Development: Beyond the Triple Bottom Line. OD Practitioner 46(4): 65-68.

24. Pizzirani S, McLaren SJ, Forster ME, Pohatu P, Porou TTW, et al. (2016) The distinctive recognition of culture within LCSA: realising the quadruple bottom line. The International Journal of Life Cycle Assessment 1-20.

25. Blassnigg M, Martha Blassnigg (2013) Transdisciplinarity: Challenges, Approaches and Opportunities at the Cusp of History, Michael Punt. Plymouth: Plymouth University, Pp: 13.

26. Gunderson D, O’Day T (2009) Permaculture as a natural systems design approach for teaching sustainability in higher education: Pacific University's B-Street permaculture project. Addressing Global Environmental Security Through Innovative Educational Curricula p p:P 165-178.

27. Jucker R (2002) Sustainability? Never heard of it!: Some basics we shouldn't ignore when engaging in education for sustainability. International Journal of Sustainability in Higher Education 3(1): 8-18.

28. Orr D (2011) Hope is an imperative: The essential David Orr. Washington, DC: Island Press.

29. Ferrall Jr, VE (2011) Liberal arts at the brink. Cambridge, MA: Harvard University Press.

30. Kilgo CA, Sheets JKE, Pascarella ET (2015) The link between high-impact practices and student learning: Some longitudinal evidence. Higher Education 69(4): 509-525.

31. Nussbaum M (2010) Not for profit: Why democracy needs the humanities. Princeton, NJ: Princeton University Press.

32. Rhodes F (2006) Sustainability: The ultimate liberal art. Chronicle of Higher Education 53(9): 24-25.

33. Seifert T, Goodman K, Lindsay, Jorgensen JD, Wolniak $\mathrm{G}$, et al. (2008) The effects of liberal arts experiences on liberal arts outcomes. Research in Higher Education 49(2): 107-125.

34. Adomßent M, Fischer D, Godemann J, Herzig C, Otte I, et al. (2014) Emerging Areas in Research on Higher Education for Sustainable Development - 


\section{Psychology \& Psychological Research International Journal}

Management Education, Sustainable Consumption and Perspectives from Central and Eastern Europe 62(1): $1-7$.

35. Barrett M (2006) Education for the environment: Action competence, becoming, and story. Environmental Education Research 12(3-4): 503-511.

36. Clark SG, Rutherford M, Auer M, Cherney D, Wallace $\mathrm{R}$, et al. (2011) College and university environmental programs as a policy problem (part 1): Integrating knowledge, education, and action for a better world? Environmental Management 47(5): 701-715.

37. Orr D (2002) Four challenges of sustainability. Conservation Biology 16(6): 1457-1460.

38. Charmaz C (2006) Constructing grounded theory: A practical guide through qualitative analysis. Los Angeles: Sage.

39. Corbin J, Strauss A (2008) Basics of qualitative research ( $3^{\text {rd }}$ ed.). Los Angeles: Sage.

40. Glaser B, Strauss A (1967) The discovery of grounded theory: Strategies for qualitative research. New York: Aldine de Gruyter 1-284.

41. Morse JM, Stern PN, Corbin JM, Bowers BJ, Charmaz K, et al. (2009) Developing grounded theory. Left Coast Pres.

42. Patton M (2002) Variety in qualitative inquiry. In Qualitative research and evaluation methods. Thousand Oaks, CA: Sage. $3^{\text {rd }}$ edition, Pp: 75-142.

43. Lewins C, Lewins A (2009) QSR NVivo8: Distinguishing features and functions. QUIC Software Reviews.

44. Welsh E (2002) Dealing with data: Using N Vivo in the qualitative data analysis process. Qualitative Social Research 3(2): 1-3.

45. Fischer J, Manning AD, Steffen W, Rose DB, Daniell K, et al. (2007) Mind the sustainability gap. TRENDS in Ecology and Evolution 22(12): 621-624.

46. Chan S, Harris J (2011) Moral development and prosocial behavior. Journal of Medical Ethics 37: 130131.

47. Clayton S (2003) Environmental identity: A conceptual and operational definition. Identity and the natural environment (pp.45-65).
48. Messick D, McClintock C (1968) Motivational basis of choice in experimental games. Journal of Experimental Social Psychology 4(1):1-25.

49. Van Lange P, Otten W, De Bruin E, Joireman JA (1997) Development of prosocial, individualistic, and competitive orientations: Theory and preliminary evidence. J Pers Soc Psychol 73(4): 733-746.

50. Clayton S, Opotow S (2003) Introduction: Identity and the natural environment. In S. Clayton \&S. Opotow (Eds.), Identity and the natural environment, Cambridge: MIT Press. Pp: 1-24.

51. Schultz P, Tabanico J (2007) Self, identity, and the natural environment: Exploring implicit connections with nature. Journal of Applied Social Psychology 37(6): 1219-1247.

52. Eugene Jr MO, Beringer A (2010) Sustainability in higher education: Psychological research for effective pedagogy. The Canadian Journal of Higher Education 40(2): 51-77.

53. Barrett M (2007) Homework and field work: Investigations into the rhetoric-reality gap in environmental education research and pedagogy. Environmental Education Research 13(2): 209-223.

54. Chandler R (2017) Implications of Attachment Theory on Social Value Orientation and Sustainability Behavior: An Annotated Bibliography.

55. Corbin J, Morse JM (2003) The unstructured interactive interview: Issues of reciprocity and risks when dealing with sensitive topics. Qualitative Inquiry 9(3): 335-354.

56. Oskamp S (2000) A sustainable future for humanity?. Am Psychol 55(5): 496-508.

57. Pickett S, Grove J (2009) Urban ecosystems: What would Tansley do?. Urban Ecosystems 12(1): 1-8.

58. Rindfleisch A, Burroughs J, Wong N (2009) The safety of objects: Materialism, existential insecurity, and brand connection. Journal of Consumer Research 36(1): 1-16.

59. Roch S, Samuelson C (1997) Effects of environmental uncertainty and social value orientation in resource dilemmas. Organizational Behavior and Human Decision Processes 70(3): 221-235. 


\section{Psychology \& Psychological Research International Journal}

60. Schultz P, Shriver C, Tabanico J, Khazian A (2004) Implicit connections with nature. Journal of Environmental Psychology 24: 31-42.

61. Van Lange P, De Cremer D, Van Dijk E, Van Vugt M (2007) Self-interest and beyond: Basic principles of social interaction. In A. W. Kruglanski \& E. T. Higgings (Eds.), Social psychology: Handbook of basic principles, New York: Guilford Pp: 540-561. 